\title{
Estrutura do componente arbóreo de uma floresta estacional na Serra do Sudeste, Rio Grande do Sul, Brasil ${ }^{1}$
}

\author{
CRISTIANE F. JURINITZ² e JOÃO A. JARENKOW ${ }^{2,3}$
}

(recebido: 6 de novembro de 2002; aceito: 11 de setembro de 2003)

\begin{abstract}
Structure of the arboreal component of a seasonal forest on Serra do Sudeste, Rio Grande do Sul, Brazil). The original forest cover in Rio Grande do Sul is strongly reduced and fragmented and, particularly on Serra do Sudeste, little is known about the structure of its forests. The finding of a primary forest remnant in the oriental slopes allowed a phytosociological survey that aims to describe the structure of the arboreal component and to establish its relations with other seasonal forests. All trees with $\mathrm{DBH} \geq 5 \mathrm{~cm}$ were recorded in an area of 1 ha, subdivided into 100 plots of $10 \times 10 \mathrm{~m}$. On the phytosociological survey 2.236 individuals were sampled, belonging to 69 species, 55 genera and 34 families. Myrtaceae, Lauraceae and Euphorbiaceae were the families with the highest species richness. Fabaceae almost do not appear in forests of Serra do Sudeste, which is contrasting with its participation in other seasonal forests in southern Brazil. Among the species with the highest importance values, some were found in high density, as Gymnanthes concolor Spreng., Esenbeckia grandiflora Mart. and Sorocea bonplandii (Baill.) W.C.Burger et al. Other species presented high values of basal area, as Sloanea monosperma Vell. and Ilex paraguariensis A.St-Hil. Some species showed intermediate values for the estimated parameters, such as Myrsine umbellata Mart., Miconia rigidiuscula Cogn., and Calyptranthes grandifolia O.Berg. Species diversity (H') was estimated as 3.204 (nats) $\left(\mathrm{J}^{\prime}=0.757\right)$, one of highest values recorded for seasonal forests in Rio Grande do Sul, in the same diversity context found for this formation elsewhere in Brazil.
\end{abstract}

Key words - arboreal diversity, phytogeography, phytosociology, seasonal forest, southern Brazil

RESUMO - (Estrutura do componente arbóreo de uma floresta estacional na Serra do Sudeste, Rio Grande do Sul, Brasil). A cobertura florestal no Rio Grande do Sul encontra-se fortemente reduzida e fragmentada e, na Serra do Sudeste, particularmente, muito pouco se sabe sobre a estrutura de suas florestas. A localização de um remanescente de floresta primária nas encostas orientais permitiu a realização de um levantamento fitossociológico com o objetivo de descrever a estrutura do componente arbóreo e estabelecer relações com outras florestas estacionais. Foram amostradas todas as árvores com DAP $\geq 5 \mathrm{~cm}$ em uma área de 1 ha, subdividida em 100 parcelas de $10 \times 10 \mathrm{~m}$. Foram registrados 2.236 indivíduos, pertencentes a 69 espécies, 55 gêneros e 34 famílias. As famílias que sobressaíram em riqueza foram Myrtaceae, Lauraceae e Euphorbiaceae. A pequena contribuição de Fabaceae nas florestas na Serra do Sudeste contrasta com sua importância em outras florestas estacionais no Rio Grande do Sul e no Brasil. Dentre as espécies com os maiores valores de importância, destacaram-se Gymnanthes concolor Spreng., Esenbeckia grandiflora Mart. e Sorocea bonplandii (Baill.) W.C.Burger et al., pela elevada densidade, Sloanea monosperma Vell. e Ilex paraguariensis A.St-Hil., pela elevada área basal, e com valores intermediários nesses parâmetros Myrsine umbellata Mart., Miconia rigidiuscula Cogn. e Calyptranthes grandifolia O.Berg. A diversidade específica (H') foi estimada em 3,204 (nats) (J' = 0,757), um dos mais altos valores já registrados para as florestas estacionais no Rio Grande do Sul e no mesmo contexto de diversidade encontrado para a formação em outras regiões no Brasil.

Palavras-chave - diversidade arbórea, fitogeografia, fitossociologia, floresta estacional, sul do Brasil

\section{Introdução}

As diferentes formações florestais presentes no Rio Grande do Sul são todas classificadas como Mata Atlântica (lato sensu) desde que o conceito deste bioma foi ampliado e passou a incluir também seus ecossistemas associados (Consórcio Mata Atlântica \& Unicamp

\footnotetext{
1. Parte da dissertação de mestrado de C.F. Jurinitz.

2. Universidade Federal do Rio Grande do Sul, Departamento de Botânica, Av. Bento Gonçalves, 9500, 91501-970 Porto Alegre, RS, Brasil.

3. Autor para correspondência: jarenkow @ portoweb.com.br
}

1992). Recentemente, Oliveira Filho \& Fontes (2000), com base em uma análise da flora arbórea no sudeste do Brasil, recomendam a utilização desse conceito amplo, embora reconheçam as diferenças florísticofisionômicas existentes entre as florestas ombrófilas e estacionais.

No entanto, as classificações tradicionais da vegetação brasileira reconhecem para o Rio Grande do Sul a ocorrência de Floresta Ombrófila Densa e Mista e ainda de Floresta Estacional Decidual e Semidecidual, além das áreas de Formações Pioneiras ou Restingas (Veloso \& Góes Filho 1982, Teixeira et al. 1986). No estado, as florestas estacionais distribuem-se no 
noroeste (região do Alto Uruguai), na região central (encostas meridionais da Serra Geral e Depressão Central) e na metade sul, a leste, nas encostas orientais da Serra do Sudeste (Teixeira et al. 1986). Dentre estas, somente as últimas e uma porção próxima a Porto Alegre (coincidente com a bacia do rio dos Sinos) é classificada como Floresta Estacional Semidecidual, sendo o restante correspondente à Floresta Estacional Decidual (Veloso \& Góes Filho 1982, Teixeira et al. 1986).

Fitogeograficamente, dois corredores de imigração de espécies arbóreas tropicais são reconhecidos no Rio Grande do Sul, os quais influenciam fortemente a composição das florestas estacionais (Rambo 1961, Jarenkow \& Waechter 2001). Esses corredores determinam a existência de dois contingentes florísticos distintos, um deles, tipicamente mesófilo ou estacional (Jarenkow \& Waechter 2001), corresponde às espécies que chegam ao estado pelo corredor formado pela Floresta Estacional Decidual do Alto Uruguai (Rambo 1956). O outro, constituído de espécies tropicais atlânticas ou higrófilas (Jarenkow \& Waechter 2001), corresponde àquelas que entram no estado através da estreita faixa de Floresta Ombrófila Densa que ocorre desde Torres (na divisa com Santa Catarina) até Osório (Rambo 1950, 1961).

A cobertura florestal no Rio Grande do Sul, que inicialmente correspondia a cerca de $40 \%$ do território, encontra-se reduzida atualmente a apenas 6,8\% da original (Fundação SOS Mata Atlântica/INPE/ISA 1998). Diante dessa situação, ainda existem regiões cuja vegetação é muito pouco conhecida, como é o caso da Serra do Sudeste, apontada como uma das principais áreas com vistas à conservação da flora regional por abrigar um grande número de espécies endêmicas em formações abertas (Guadagnin et al. 2000).

As primeiras descrições a respeito das florestas da Serra do Sudeste são de Ihering (1891), seguido de Lindman (1906) e Rambo (1942), que tratam de aspectos mais fisionômicos da região. Outras abordagens, também essencialmente florísticofisionômicas e abrangendo extensas áreas, são fornecidas por Reitz et al. (1983), Teixeira et al. (1986) e Leite (1995). Excetuando-se a região da Grande Porto Alegre, até o momento o único estudo mais detalhado, que fornece dados quantitativos, foi realizado por Souza (2001) praticamente no limite sul de ocorrência destas florestas.

As áreas de encosta, principalmente das Serras Geral e do Sudeste, comportam grande parte dos remanescentes florestais no Rio Grande do Sul, poupados por serem áreas íngremes e de difícil acesso. Esses remanescentes têm um papel importante como corredores ecológicos, capazes de proporcionar o fluxo gênico entre populações isoladas, um fator tido como crítico para a conservação de muitas espécies devido à fragmentação a que estão submetidos os hábitats florestais (Kageyama \& Gandara 2000, Silva \& Tabarelli 2000).

O presente estudo foi realizado em um dos poucos remanescentes de floresta primária na encosta da Serra do Sudeste. O trabalho teve como objetivo determinar a composição e a estrutura do componente arbóreo, estabelecendo relações com outras matas estacionais sul-rio-grandenses e brasileiras. Estes dados são importantes para a compreensão da estrutura original das florestas no Rio Grande do Sul, além de fornecerem subsídios para o planejamento de ações de conservação, manejo e restauração das formações florestais em uma região muito alterada pela ação antrópica e que não conta com a proteção de unidades de conservação.

\section{Material e métodos}

A área de estudo situa-se no município de Camaquã, Rio Grande do Sul, a cerca de $30^{\circ} 41^{\prime}$ 'S e $51^{\circ} 53^{\prime}$ W, no distrito de Santa Auta, localidade conhecida como Água Grande (figura 1). O remanescente florestal possui aproximadamente 170 ha e distribui-se em duas encostas que formam um vale, tendo o arroio Geraldino ao fundo. A encosta de exposição leste encontra-se bastante alterada pela ação antrópica, enquanto a oeste mantém sua cobertura florestal em bom estado de conservação, tendo sido selecionada para o presente estudo. Nesta, o trecho amostrado localizou-se entre as cotas altimétricas de 240 e 360 m.s.m.

O clima na região, assim como na maior parte do Rio Grande do Sul, é subtropical úmido, do tipo Cfa conforme a classificação de Köppen (Moreno 1961). Segundo dados coletados pela Estação Climatológica Auxiliar de Camaquã ( $30^{\circ} 48^{\prime}$ 'S e 51 $49^{\prime}$ ' W; 90,6 m.s.m.) no período de outubro de 1993 a dezembro de 2001, as médias anuais de temperatura e precipitação são, respectivamente, $18,5 \pm 0,3{ }^{\circ} \mathrm{C}$ e $1.735 \pm$ $235,1 \mathrm{~mm}$.

O município pertence à região fisiográfica da Serra do Sudeste, definida pelo substrato granítico do Escudo Cristalino Sul-Rio-Grandense, que faz parte do domínio geológico dos Terrenos Pré-Cambrianos (Kaul 1990). Os solos na região são classificados como predominantemente Podzólicos Vermelho-Amarelos, que são solos minerais, não hidromórficos, pouco profundos a profundos, caracterizados pela presença de um horizonte B textural de coloração vermelho-amarelada (Ker et al. 1986).

Os solos na área de estudo foram caracterizados a partir de 15 perfurações com um trado holandês distribuídas sistematicamente no local da amostragem. As análises foram 
realizadas no Laboratório de Análises de Solos da Faculdade de Agronomia da Universidade Federal do Rio Grande do Sul (tabela 1). Conforme essas análises e seguindo-se recomendações para a utilização agrícola (Tomé Júnior 1997), classifica-se este solo como de textura média, com suscetibilidade baixa a moderada à erosão. Apresenta teores médios de matéria orgânica e $\mathrm{pH}$ muito baixo, assim como os teores de fósforo; possui baixas quantidades de cálcio trocável, tendo o alumínio trocável, o cobre e o zinco apresentado teores médios. A porcentagem de saturação do alumínio na capacidade de troca de cátions variou de baixa $(0-40 \mathrm{~cm})$ a média $(40-60 \mathrm{~cm})$, e, portanto, este solo não apresenta caráter álico. A baixa saturação de bases mostra que se trata de um solo distrófico.

O remanescente estudado é classificado como Floresta Estacional Semidecidual Submontana (Teixeira et al. 1986) e encontra-se circundado por áreas agrícolas. Uma característica que merece destaque é a elevada abundância de afloramentos rochosos nas encostas dessa região. A amostragem do componente arbóreo foi realizada utilizando-se o método de parcelas contíguas, com dimensões de $10 \mathrm{~m} \times 10 \mathrm{~m}\left(100 \mathrm{~m}^{2}\right)$.
Foram demarcadas 100 unidades amostrais (totalizando 1 ha), nas quais registraram-se todos os indivíduos lenhosos vivos, exceto lianas, com o diâmetro do caule à altura do peito (DAP, a 1,3 $\mathrm{m}$ do solo) igual ou maior do que $5 \mathrm{~cm}$. As árvores mortas e ainda em pé foram anotadas, mas excluídas da análise estrutural. Os indivíduos ramificados abaixo de 1,3 $\mathrm{m}$ foram incluídos desde que uma de suas ramificações tivesse o diâmetro mínimo de inclusão, sendo todas as demais utilizadas no cálculo de uma única área basal, posteriormente utilizada nas estimativas de cobertura. Foram considerados dentro de uma unidade amostral os indivíduos com mais da metade do seu caule no interior da mesma. Cada indivíduo amostrado também teve sua altura total estimada (com arredondamento a cada metro) por comparação a uma vara de coleta de altura conhecida.

A coleta e a herborização do material testemunho seguiu as recomendações de Fidalgo \& Bononi (1984), sendo as exsicatas incorporadas ao Herbário do Departamento de Botânica da Universidade Federal do Rio Grande do Sul (ICN). A identificação das espécies foi realizada por meio de comparações ao material do referido herbário, consultas à

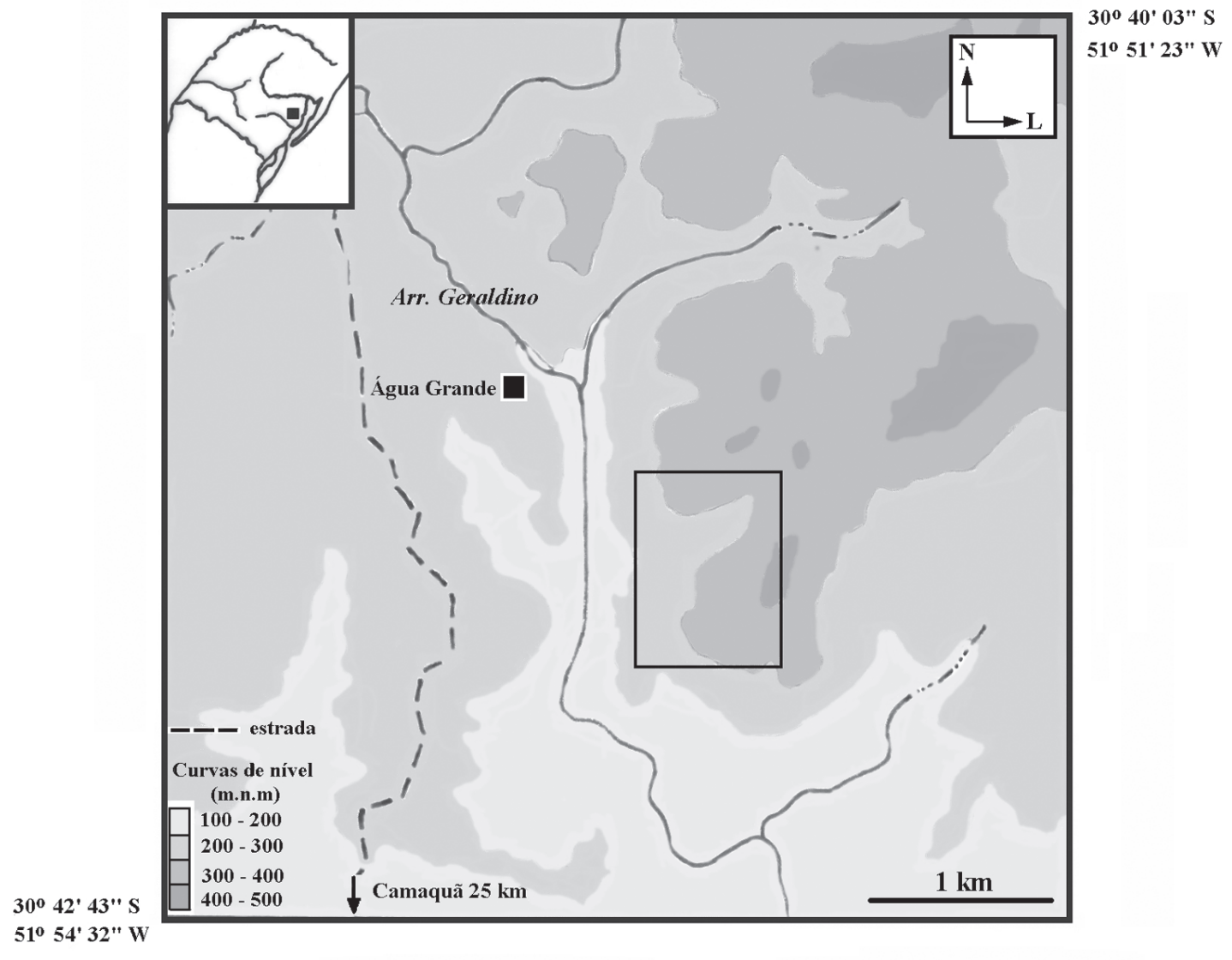

Figura 1. Localização do município de Camaquã no Rio Grande do Sul (canto superior esquerdo) e detalhe do distrito de Santa Auta, onde se localiza a área de estudo (retângulo) (adaptado da Folha SH.22-Y-B-V-1 - Cerro Negro, Serviço Geográfico do Exército, 1969).

Figure 1. Location of the Camaquã municipality in Rio Grande do Sul (upper corner left) and Santa Auta district detail, where the study site is located (rectangle) (adapted from the Sheet SH.22-Y-B-V-1 - "Cerro Negro", "Serviço Geográfico do Exército", 1969). 
Tabela 1. Parâmetros físicos e químicos analisados nas amostras de solo coletadas na área do levantamento fitossociológico realizado na mata de encosta em Camaquã (RS).

Table 1. Physical and chemical parameters analised on the soil samples collected at the site of the phytosociological survey in the slope forest at Camaquã (RS).

\begin{tabular}{|c|c|c|c|}
\hline \multirow[b]{2}{*}{ Análises } & \multicolumn{3}{|c|}{ Profundidade $(\mathrm{cm})$} \\
\hline & $0-20$ & $20-40$ & $40-60$ \\
\hline Areia fina $(\%)$ & 13 & 16 & 13 \\
\hline Areia grossa $(\%)$ & 60 & 52 & 60 \\
\hline Silte $(\%)$ & 6 & 10 & 6 \\
\hline Argila (\%) & 21 & 22 & 21 \\
\hline pH (água) & 4,7 & 4,5 & 4,6 \\
\hline M.O. (\%) & 4,1 & 2,0 & 1,8 \\
\hline $\mathrm{P}\left(\mathrm{mg} \cdot \mathrm{L}^{-1}\right)$ & 4,4 & 3,1 & 4,0 \\
\hline $\mathrm{K}\left(\mathrm{mg} \cdot \mathrm{L}^{-1}\right)$ & 129 & 83 & 67 \\
\hline $\mathrm{Al}_{\text {troc. }}\left(\mathrm{cmol}_{\mathrm{c}} \cdot \mathrm{L}^{-1}\right)$ & 0,6 & 0,8 & 1,1 \\
\hline $\mathrm{Ca}_{\text {troc. }}\left(\mathrm{cmol}_{\mathrm{c}} \cdot \mathrm{L}^{-1}\right)$ & 1,9 & 0,9 & 0,8 \\
\hline $\mathrm{Mg}_{\text {troc }}\left(\mathrm{cmol}_{\mathrm{c}} \cdot \mathrm{L}^{-1}\right)$ & 0,6 & 0,5 & 0,3 \\
\hline $\mathrm{Al}+\mathrm{H}\left(\mathrm{cmol}_{\mathrm{c}} \cdot \mathrm{L}^{-1}\right)$ & 6,1 & 4,7 & 5,1 \\
\hline $\mathrm{CTC}\left(\mathrm{cmol}_{\mathrm{c}} \cdot \mathrm{L}^{-1}\right)$ & 9,1 & 6,4 & 6,5 \\
\hline $\mathrm{S}\left(\mathrm{mg} \cdot \mathrm{L}^{-1}\right)$ & 13 & 11 & 6,6 \\
\hline $\mathrm{Zn}\left(\mathrm{mg} \cdot \mathrm{L}^{-1}\right)$ & 3,8 & 2,1 & 3,1 \\
\hline $\mathrm{Cu}\left(\mathrm{mg} \cdot \mathrm{L}^{-1}\right)$ & 0,4 & 0,3 & 0,3 \\
\hline $\mathrm{B}\left(\mathrm{mg} \cdot \mathrm{L}^{-1}\right)$ & 1,0 & 0,6 & 0,7 \\
\hline Mn (mg.L $\left.L^{-1}\right)$ & 87 & 45 & 41 \\
\hline Saturação de bases (\%) & 31 & 25 & 20 \\
\hline Saturação de Al (\%) & 6,6 & 12,6 & 17,0 \\
\hline
\end{tabular}

literatura e a especialistas. Para Pteridophyta, utilizou-se o sistema de classificação de Tryon \& Tryon (1982), enquanto que para Magnoliophyta a delimitação das famílias seguiu APG II (2003).

Os parâmetros fitossociológicos calculados foram os de densidade, freqüência e dominância, absolutas e relativas, e o valor de importância (Mueller-Dombois \& Ellenberg 1974). Na apresentação dos resultados, o valor de importância foi dividido por três, como sugerem Holdridge et al. (1971), pois dessa forma sua interpretação é facilitada, uma vez que o valor volta a representar uma porcentagem. A diversidade do componente arbóreo foi estimada através do índice de Shannon (H') e a equabilidade pelo índice de Pielou (J') (Kent \& Coker 1992).

\section{Resultados}

A riqueza na área amostrada foi de 69 espécies, distribuídas em 55 gêneros e 34 famílias (tabela 2). Myrtaceae apresentou o maior número de espécies (nove), seguida de Lauraceae, com sete espécies, Euphorbiaceae, com cinco e Flacourtiaceae, com quatro espécies. Em outro extremo, 20 famílias (59\%) estiveram representadas por apenas uma espécie.

No hectare analisado, foram inventariados 2.236 indivíduos vivos, valor que corresponde à densidade total por área, além de 36 indivíduos mortos e ainda em pé. As maiores densidades absolutas foram apresentadas por Gymnanthes concolor e Esenbeckia grandiflora (tabela 3), ambas arvoretas típicas de sub-bosque, em geral com indivíduos de pequena área basal. Metade das espécies amostradas apresentou menos de dez indivíduos, sendo que $19 \%$ tiveram apenas um único indivíduo amostrado.

A área basal total encontrada foi de $37,566 \mathrm{~m}^{2}$.ha ${ }^{-1}$, desconsiderando-se os indivíduos mortos. As três primeiras espécies em ordem de dominância absoluta foram Sloanea monosperma, Ilex paraguariensis e Myrsine umbellata, que juntas acumularam 25\% da área basal total $\left(9,526 \mathrm{~m}^{2}\right)$, sendo importantes na composição do dossel da mata. Cedrela fissilis, Alchornea triplinervia e Schefflera morototoni são igualmente espécies de grande porte que compõem o dossel, tendo apresentado altos valores de área basal para um número relativamente pequeno de indivíduos amostrados. No outro extremo dos valores de dominância absoluta estiveram 44 espécies, para as quais os valores individuais foram inferiores a $0,5 \mathrm{~m}^{2} \cdot \mathrm{ha}^{-1}$, somando cerca de $20 \%$ da área basal total.

O maior valor de importância foi apresentado por Gymnanthes concolor, que, juntamente com Esenbeckia grandiflora, em quarto lugar e Sorocea bonplandii, em sexto, destacaram-se pelos valores elevados de densidade e freqüência. Sloanea monosperma acumulou o segundo maior valor de importância pela grande área basal de seus indivíduos. Miconia rigidiuscula, Calyptranthes grandifolia, Sebastiania commersoniana, Trichilia claussenii e Casearia sylvestris, ainda entre as dez primeiras posições em valor de importância, apresentaram as estimativas dos três parâmetros que compõem este índice muito semelhantes entre si. Em geral, essas espécies tiveram muitos indivíduos no levantamento, portanto, valores altos de densidade, mas caracteristicamente atingiram diâmetros médios que, somados, resultaram em valores igualmente altos de dominância.

As quatro primeiras espécies somaram um quarto do valor de importância total, enquanto as dez primeiras acumularam a metade. No extremo inferior, 38 espécies apresentaram valor de importância menor do que $1 \%$, as quais juntas perfizeram cerca de $12 \%$ do total. 
Tabela 2. Espécies amostradas no levantamento fitossociológico do componente arbóreo na mata de encosta em Camaquã (RS), seus respectivos nomes populares e números de coleta (os números de coleta são de C.F. Jurinitz; NC = não coletada).

Table 2. Species sampled in the phytosociological survey of the arboreal component in the slope forest at Camaquã (RS), its common names and collection numbers (all the collection numbers from C.F. Jurinitz; NC = not collected).

\begin{tabular}{|c|c|c|c|}
\hline Família & Espécie & Nome popular & N. de coleta \\
\hline ANACARDIACEAE & Lithraea brasiliensis Marchand & aroeira-brava & 61 \\
\hline ANNONACEAE & Rollinia silvatica (A. St.-Hil.) Mart. & araticum-do-mato & 253 \\
\hline \multirow[t]{3}{*}{ AQUIFOLIACEAE } & Ilex brevicuspis Reissek & caúna-da-serra & 85 \\
\hline & Ilex dumosa Reissek & caúna & 66 \\
\hline & Ilex paraguariensis A. St.-Hil. & erva-mate & 60 \\
\hline ARALIACEAE & $\begin{array}{l}\text { Schefflera morototoni (Aubl.) Maguire, } \\
\text { Steyermark \& Frodin }\end{array}$ & caixeta & $\mathrm{NC}$ \\
\hline ARECACEAE & Syagrus romanzoffiana (Cham.) Glassman & jerivá & $\mathrm{NC}$ \\
\hline ASTERACEAE & Vernonia discolor (Spreng.) Less. & vassourão-preto & 219 \\
\hline BORAGINACEAE & Cordia ecalyculata Vell. & louro-preto & 249 \\
\hline \multirow[t]{2}{*}{ CANNABACEAE } & Celtis iguanaea (Jacq.) Sarg. & taleiro & 175 \\
\hline & Trema micrantha (L.) Blume & grandiúva & 83 \\
\hline CYATHEACEAE & Alsophila setosa Kaulf. & xaxim-de-espinho & 147 \\
\hline EBENACEAE & Diospyros inconstans Jacq. & maria-preta & 251 \\
\hline ELAEOCARPACEAE & Sloanea monosperma Vell. & sapopema & 242 \\
\hline ERYTHROXYLACEAE & Erythroxylum argentinum Schulz & cocão & 274 \\
\hline \multirow[t]{5}{*}{ EUPHORBIACEAE } & Alchornea triplinervia (Spreng.) Müll. Arg. & tanheiro & 92 \\
\hline & Gymnanthes concolor Spreng. & laranjeira-do-mato & 54 \\
\hline & Pachystroma longifolium (Nees) I.M. Johnst. & mata-olho & 143 \\
\hline & $\begin{array}{l}\text { Sebastiania commersoniana (Baill.) } \\
\quad \text { L.B. Sm. \& Downs }\end{array}$ & branquilho & 250 \\
\hline & Sebastiania serrata (Klotzsch) Müll. Arg. & branquilho & 50 \\
\hline FABACEAE & Inga cf. virescens Benth. & ingá & 247 \\
\hline ICACINACEAE & Citronella paniculata (Mart.) R.A. Howard & congonha & 245 \\
\hline LAMIACEAE & Vitex megapotamica (Spreng.) Moldenke & tarumã & 65 \\
\hline \multirow[t]{7}{*}{ LAURACEAE } & Aiouea saligna Meisn. & canela-anhoaíba & 296 \\
\hline & Nectandra grandiflora Nees & canela-amarela & 46 \\
\hline & Nectandra megapotamica (Spreng.) Mez & canela-preta & 234 \\
\hline & Nectandra oppositifolia Nees & canela-ferrugem & 264 \\
\hline & Ocotea puberula (A. Rich.) Nees & canela-parda & 265 \\
\hline & Ocotea pulchella (Nees) Mez & canela-preta & 62 \\
\hline & Ocotea silvestris Vattimo & - & 203 \\
\hline MELASTOMATACEAE & Miconia rigidiuscula Cogn. & pixiricão & 196 \\
\hline \multirow[t]{3}{*}{ MELIACEAE } & Cabralea canjerana (Vell.) Mart. & canjerana & $\mathrm{NC}$ \\
\hline & Cedrela fissilis Vell. & cedro & 244 \\
\hline & Trichilia claussenii C.DC. & catiguá-vermelho & 257 \\
\hline \multirow[t]{2}{*}{ MONIMIACEAE } & Hennecartia omphalandra Poiss. & gema-de-ovo & 258 \\
\hline & Mollinedia schottiana (Spreng.) Perkins & pimenteira & 236 \\
\hline \multirow[t]{3}{*}{ MORACEAE } & Ficus luschnathiana (Miq.) Miq. & - & 190 \\
\hline & Ficus organensis (Miq.) Miq. & figueira-de-folha-miúda & 243 \\
\hline & Sorocea bonplandii (Baill.) W.C. Burger, Lanj. \& Boer & cincho & $\mathrm{NC}$ \\
\hline \multirow[t]{2}{*}{ MYRSINACEAE } & Myrsine parvula (Mez) Otegui & capororoca & 177 \\
\hline & Myrsine umbellata Mart. & capororoca & 63 \\
\hline \multirow[t]{4}{*}{ MYRTACEAE } & Calyptranthes grandifolia O. Berg & guamirim-chorão & 148 \\
\hline & Eugenia involucrata DC. & cerejeira & 47 \\
\hline & Eugenia ramboi D. Legrand & batinga & $\mathrm{NC}$ \\
\hline & Eugenia rostrifolia D. Legrand & batinga-vermelha & 207 \\
\hline
\end{tabular}


continuação

\begin{tabular}{|c|c|c|c|}
\hline Família & Espécie & Nome popular & N. de coleta \\
\hline \multirow[t]{5}{*}{ MYRTACEAE } & Eugenia schuechiana O. Berg & guamirim & 252 \\
\hline & Myrcia glabra (O. Berg) D. Legrand & ubá & 169 \\
\hline & Myrcianthes gigantea (D. Legrand) D. Legrand & araçá-do-mato & 287 \\
\hline & Myrciaria cuspidata O. Berg & camboim & 288 \\
\hline & Neomitranthes gemballae (D. Legrand) D. Legrand & pau-ferro & 267 \\
\hline \multirow[t]{2}{*}{ NYCTAGINACEAE } & Guapira opposita (Vell.) Reitz & maria-mole & 266 \\
\hline & Pisonia ambigua Heimerl & maria-faceira & 286 \\
\hline PROTEACEAE & Roupala brasiliensis Klotzsch & carvalho-brasileiro & 129 \\
\hline ROSACEAE & Prunus sellowii Koehne & pessegueiro-do-mato & 268 \\
\hline RUBIACEAE & Faramea marginata Cham. & pimenteira-selvagem & 36 \\
\hline \multirow[t]{2}{*}{ RUTACEAE } & Esenbeckia grandiflora Mart. & pau-de-cutia & 38 \\
\hline & Zanthoxylum rhoifolium Lam. & mamica-de-cadela & 235 \\
\hline SABIACEAE & Meliosma selowii Urb. & pau-fernandes & 259 \\
\hline \multirow[t]{4}{*}{ SALICACEAE } & Banara parviflora (A. Gray) Benth. & farinha-seca & 290 \\
\hline & Casearia decandra Jacq. & guaçatunga & 48 \\
\hline & Casearia sylvestris $\mathrm{Sw}$. & chá-de-bugre & 78 \\
\hline & Xylosma pseudosalzmannii Sleumer & sucará & 272 \\
\hline \multirow[t]{3}{*}{ SAPINDACEAE } & Allophylus edulis (A. St.-Hil.) Radlk. ex Warm. & chal-chal & 239 \\
\hline & Cupania vernalis Cambess. & camboatá-vermelho & 186 \\
\hline & Matayba elaeagnoides Radlk. & camboatá & 69 \\
\hline \multirow[t]{2}{*}{ SAPOTACEAE } & Chrysophyllum gonocarpum (Mart. \& Eichler) Engl. & aguaí-da-serra & 282 \\
\hline & Chrysophyllum marginatum (Hook. \& Arn.) Radlk. & aguaí-vermelho & $\mathrm{NC}$ \\
\hline SOLANACEAE & Solanum sanctaecatharinae Dunal & joá-manso & 260 \\
\hline SYMPLOCACEAE & Symplocos tetrandra (Mart.) Miq. & pau-de-cangalha & 37 \\
\hline
\end{tabular}

A estimativa da diversidade de Shannon ( $\left.\mathrm{H}^{\prime}\right)$ resultou em 3,204 (nats) e a equabilidade de Pielou (J') em 0,757. Ao considerar a alteração do critério de inclusão de 5 para $10 \mathrm{~cm}$ de DAP mínimo, apesar do número de espécies ter apresentado uma pequena redução (cinco espécies), esses valores aumentaram, passando para $\mathrm{H}^{\prime}=3,548$ (nats) e $\mathrm{J}^{\prime}=0,853$. $\mathrm{O}$ incremento da diversidade estimada pode ser explicado pelo fato do índice de Shannon ser influenciado não apenas pela riqueza, mas também pela proporcionalidade da abundância entre as espécies. Dessa forma, com a alteração do critério de inclusão há eliminação de grande parte dos indivíduos pertencentes a poucas espécies (notadamente as típicas do sub-bosque), aumentando a equabilidade (tabela 4).

A distribuição do número de indivíduos (em porcentagem do total) por classes de diâmetro evidenciou a predominância dos indivíduos característicos do subbosque na amostragem, como mostra a grande concentração destes na primeira classe considerada (figura 2). As quatro primeiras classes de diâmetro tratadas conjuntamente revelaram que $93 \%$ dos indivíduos amostrados tinham o diâmetro à altura do peito entre 5 e $25 \mathrm{~cm}$. O maior diâmetro encontrado foi de 94,5 cm, de um indivíduo de Cedrela fissilis.

Com relação à estrutura vertical, a distribuição dos indivíduos nas diferentes alturas estimadas não possibilitou o reconhecimento de picos nítidos que poderiam evidenciar estratos no componente arbóreo (figura 3). Assim como nas análises anteriores, a acentuada participação dos indivíduos de sub-bosque na amostragem é demonstrada na grande concentração destes entre $4 \mathrm{~m}$ e $14 \mathrm{~m}$ de altura. A partir daí, há um decréscimo progressivo em seu número à medida que as alturas aumentam, até atingir-se $24 \mathrm{~m}$, a maior altura estimada, para dois indivíduos, um de Ocotea puberula e outro de Roupala brasiliensis.

\section{Discussão}

Myrtaceae destaca-se em riqueza específica em levantamentos fitossociológicos nas diferentes formações florestais no Rio Grande do Sul (Jarenkow \& Baptista 1987, Dillenburg et al. 1992, Jarenkow 1994, Waechter \& Jarenkow 1998, Waechter et al. 2000). Nas Regiões Sul e Sudeste do Brasil, de um modo geral, 
Tabela 3. Parâmetros fitossociológicos calculados para o componente arbóreo amostrado na mata de encosta em Camaquã (RS), em ordem decrescente de valor de importância (VI) (DA = densidade absoluta, DR = densidade relativa, FA = freqüência absoluta, $\mathrm{FR}$ = frequiência relativa, $\mathrm{DoA}=$ dominância absoluta e DoR = dominância relativa).

Table 3. Phytosociological parameters calculated for the arboreal component sampled in the slope forest at Camaquã (RS), ranked according to importance value $(\mathrm{VI})(\mathrm{DA}=$ absolute density, $\mathrm{DR}=$ relative density, $\mathrm{FA}=$ absolute frequency, $\mathrm{FR}=$ relative frequency, $\mathrm{DoA}=$ absolute dominance and $\mathrm{DoR}=$ relative dominance $)$.

\begin{tabular}{|c|c|c|c|c|c|c|c|c|}
\hline & Espécie & $\begin{array}{c}\text { DA } \\
\left(\text { ind.ha }^{-1}\right)\end{array}$ & $\begin{array}{l}\mathrm{DR} \\
(\%)\end{array}$ & $\begin{array}{l}\text { FA } \\
(\%)\end{array}$ & $\begin{array}{l}\mathrm{FR} \\
(\%)\end{array}$ & $\begin{array}{c}\text { DoA } \\
\left(\mathrm{m}^{2} \cdot \mathrm{ha}^{-1}\right)\end{array}$ & $\begin{array}{r}\text { DoR } \\
(\%)\end{array}$ & $\begin{array}{l}\text { VI } \\
(\%)\end{array}$ \\
\hline 1. & Gymnanthes concolor & 486,0 & 21,74 & 84,0 & 7,60 & 1,902 & 5,06 & 11,47 \\
\hline 2. & Sloanea monosperma & 33,0 & 1,48 & 30,0 & 2,71 & 4,614 & 12,28 & 5,49 \\
\hline 3. & Myrsine umbellata & 106,0 & 4,74 & 46,0 & 4,16 & 2,374 & 6,32 & 5,07 \\
\hline 4. & Esenbeckia grandiflora & 155,0 & 6,93 & 66,0 & 5,97 & 0,668 & 1,78 & 4,89 \\
\hline 5. & Miconia rigidiuscula & 135,0 & 6,04 & 45,0 & 4,07 & 1,244 & 3,31 & 4,47 \\
\hline 6. & Sorocea bonplandii & 122,0 & 5,46 & 70,0 & 6,33 & 0,456 & 1,21 & 4,33 \\
\hline 7. & Calyptranthes grandifolia & 85,0 & 3,80 & 52,0 & 4,71 & 1,563 & 4,16 & 4,22 \\
\hline 8. & Sebastiania commersoniana & 104,0 & 4,65 & 45,0 & 4,07 & 1,471 & 3,91 & 4,21 \\
\hline 9. & Trichilia claussenii & 104,0 & 4,65 & 45,0 & 4,07 & 1,392 & 3,70 & 4,14 \\
\hline 10. & Casearia sylvestris & 103,0 & 4,61 & 50,0 & 4,52 & 1,097 & 2,92 & 4,02 \\
\hline 11. & Ilex paraguariensis & 37,0 & 1,65 & 27,0 & 2,44 & 2,538 & 6,76 & 3,62 \\
\hline 12. & Neomitranthes gemballae & 61,0 & 2,73 & 44,0 & 3,98 & 1,093 & 2,91 & 3,21 \\
\hline 13. & Alsophila setosa & 118,0 & 5,28 & 22,0 & 1,99 & 0,821 & 2,19 & 3,15 \\
\hline 14. & Pachystroma longifolium & 36,0 & 1,61 & 17,0 & 1,54 & 1,104 & 2,94 & 2,03 \\
\hline 15. & Roupala brasiliensis & 29,0 & 1,30 & 23,0 & 2,08 & 0,925 & 2,46 & 1,95 \\
\hline 16. & Myrcia glabra & 26,0 & 1,16 & 22,0 & 1,99 & 0,838 & 2,23 & 1,79 \\
\hline 17. & Hennecartia omphalandra & 40,0 & 1,79 & 29,0 & 2,62 & 0,344 & 0,91 & 1,78 \\
\hline 18. & Cabralea canjerana & 22,0 & 0,98 & 18,0 & 1,63 & 0,773 & 2,06 & 1,56 \\
\hline 19. & Alchornea triplinervia & 17,0 & 0,76 & 13,0 & 1,18 & 1,007 & 2,68 & 1,54 \\
\hline 20. & Myrsine parvula & 31,0 & 1,39 & 20,0 & 1,81 & 0,480 & 1,28 & 1,49 \\
\hline 21. & Cedrela fissilis & 7,0 & 0,31 & 7,0 & 0,63 & 1,291 & 3,44 & 1,46 \\
\hline 22. & Faramea marginata & 35,0 & 1,57 & 28,0 & 2,53 & 0,099 & 0,26 & 1,45 \\
\hline 23. & Eugenia rostrifolia & 18,0 & 0,81 & 18,0 & 1,63 & 0,611 & 1,63 & 1,35 \\
\hline 24. & Aiouea saligna & 27,0 & 1,21 & 18,0 & 1,63 & 0,441 & 1,17 & 1,34 \\
\hline 25. & Chrysophyllum gonocarpum & 20,0 & 0,89 & 18,0 & 1,63 & 0,542 & 1,44 & 1,32 \\
\hline 26. & Zanthoxylum rhoifolium & 26,0 & 1,16 & 21,0 & 1,90 & 0,247 & 0,66 & 1,24 \\
\hline 27. & Nectandra megapotamica & 17,0 & 0,76 & 16,0 & 1,45 & 0,559 & 1,49 & 1,23 \\
\hline 28. & Nectandra oppositifolia & 18,0 & 0,81 & 14,0 & 1,27 & 0,470 & 1,25 & 1,11 \\
\hline 29. & Schefflera morototoni & 8,0 & 0,36 & 8,0 & 0,72 & 0,840 & 2,24 & 1,11 \\
\hline 30. & Casearia decandra & 21,0 & 0,94 & 18,0 & 1,63 & 0,247 & 0,66 & 1,07 \\
\hline 31. & Myrciaria cuspidata & 23,0 & 1,03 & 20,0 & 1,81 & 0,134 & 0,36 & 1,07 \\
\hline 32. & Ilex brevicuspis & 15,0 & 0,67 & 11,0 & 1,00 & 0,485 & 1,29 & 0,99 \\
\hline 33. & Prunus sellowii & 11,0 & 0,49 & 9,0 & 0,81 & 0,517 & 1,38 & 0,89 \\
\hline 34. & Ocotea pulchella & 7,0 & 0,31 & 7,0 & 0,63 & 0,626 & 1,67 & 0,87 \\
\hline 35. & Ocotea silvestris & 10,0 & 0,45 & 10,0 & 0,90 & 0,221 & 0,59 & 0,65 \\
\hline 36. & Guapira opposita & 15,0 & 0,67 & 12,0 & 1,09 & 0,055 & 0,15 & 0,63 \\
\hline 37. & Ficus luschnathiana & 6,0 & 0,27 & 6,0 & 0,54 & 0,392 & 1,04 & 0,62 \\
\hline 38. & Xylosma pseudosalzmannii & 9,0 & 0,40 & 9,0 & 0,81 & 0,216 & 0,57 & 0,60 \\
\hline 39. & Banara parviflora & 9,0 & 0,40 & 9,0 & 0,81 & 0,202 & 0,54 & 0,59 \\
\hline 40. & Cupania vernalis & 12,0 & 0,54 & 8,0 & 0,72 & 0,164 & 0,44 & 0,57 \\
\hline 41. & Matayba elaeagnoides & 6,0 & 0,27 & 5,0 & 0,45 & 0,349 & 0,93 & 0,55 \\
\hline 42. & Allophylus edulis & 8,0 & 0,36 & 8,0 & 0,72 & 0,158 & 0,42 & 0,50 \\
\hline 43. & Nectandra grandiflora & 6,0 & 0,27 & 6,0 & 0,54 & 0,152 & 0,40 & 0,41 \\
\hline 44. & Myrcianthes gigantea & 5,0 & 0,22 & 5,0 & 0,45 & 0,104 & 0,28 & 0,32 \\
\hline
\end{tabular}


continuação

\begin{tabular}{|c|c|c|c|c|c|c|c|c|}
\hline & Espécie & $\begin{array}{c}\text { DA } \\
\left(\text { ind.ha }^{-1} \text { ) }\right.\end{array}$ & $\begin{array}{l}\mathrm{DR} \\
(\%)\end{array}$ & $\begin{array}{l}\text { FA } \\
(\%)\end{array}$ & $\begin{array}{l}\text { FR } \\
(\%)\end{array}$ & $\begin{array}{c}\text { DoA } \\
\left(\mathrm{m}^{2} \cdot \mathrm{ha}^{-1}\right)\end{array}$ & $\begin{array}{c}\text { DoR } \\
(\%)\end{array}$ & $\begin{array}{l}\text { VI } \\
(\%)\end{array}$ \\
\hline 45. & Ocotea puberula & 2,0 & 0,09 & 2,0 & 0,18 & 0,234 & 0,62 & 0,30 \\
\hline 46. & Pisonia ambigua & 3,0 & 0,13 & 2,0 & 0,18 & 0,211 & 0,56 & 0,29 \\
\hline 47. & Syagrus romanzoffiana & 4,0 & 0,18 & 4,0 & 0,36 & 0,113 & 0,30 & 0,28 \\
\hline 48. & Diospyros inconstans & 3,0 & 0,13 & 3,0 & 0,27 & 0,143 & 0,38 & 0,26 \\
\hline 49. & Erythroxylum argentinum & 3,0 & 0,13 & 3,0 & 0,27 & 0,127 & 0,34 & 0,25 \\
\hline 50. & Lithraea brasiliensis & 4,0 & 0,18 & 4,0 & 0,36 & 0,067 & 0,18 & 0,24 \\
\hline 51. & Vernonia discolor & 2,0 & 0,09 & 2,0 & 0,18 & 0,147 & 0,39 & 0,22 \\
\hline 52. & Ficus organensis & 1,0 & 0,04 & 1,0 & 0,09 & 0,186 & 0,50 & 0,21 \\
\hline 53. & Symplocos tetrandra & 4,0 & 0,18 & 4,0 & 0,36 & 0,029 & 0,08 & 0,21 \\
\hline 54. & Meliosma sellowii & 2,0 & 0,09 & 2,0 & 0,18 & 0,104 & 0,28 & 0,18 \\
\hline 55. & Chrysophyllum marginatum & 3,0 & 0,13 & 3,0 & 0,27 & 0,029 & 0,08 & 0,16 \\
\hline 56. & Vitex megapotamica & 1,0 & 0,04 & 1,0 & 0,09 & 0,087 & 0,23 & 0,12 \\
\hline 57. & Eugenia involucrata & 2,0 & 0,09 & 2,0 & 0,18 & 0,034 & 0,09 & 0,12 \\
\hline 58. & Citronella paniculata & 2,0 & 0,09 & 2,0 & 0,18 & 0,034 & 0,09 & 0,12 \\
\hline 59. & Sebastiania serrata & 1,0 & 0,04 & 1,0 & 0,09 & 0,058 & 0,15 & 0,10 \\
\hline 60. & Cordia ecalyculata & 1,0 & 0,04 & 1,0 & 0,09 & 0,050 & 0,13 & 0,09 \\
\hline 61. & Celtis iguanaea & 1,0 & 0,04 & 1,0 & 0,09 & 0,023 & 0,06 & 0,07 \\
\hline 62. & Inga cf. virescens & 1,0 & 0,04 & 1,0 & 0,09 & 0,020 & 0,05 & 0,06 \\
\hline 63. & Eugenia ramboi & 1,0 & 0,04 & 1,0 & 0,09 & 0,014 & 0,04 & 0,06 \\
\hline 64. & Solanum sanctaecatharinae & 1,0 & 0,04 & 1,0 & 0,09 & 0,011 & 0,03 & 0,05 \\
\hline 65. & Trema micrantha & 1,0 & 0,04 & 1,0 & 0,09 & 0,009 & 0,02 & 0,05 \\
\hline 66. & Ilex dumosa & 1,0 & 0,04 & 1,0 & 0,09 & 0,006 & 0,02 & 0,05 \\
\hline 67. & Rollinia silvatica & 1,0 & 0,04 & 1,0 & 0,09 & 0,005 & 0,01 & 0,05 \\
\hline 68. & Eugenia schuechiana & 1,0 & 0,04 & 1,0 & 0,09 & 0,003 & 0,01 & 0,05 \\
\hline 69. & Mollinedia schottiana & 1,0 & 0,04 & 1,0 & 0,09 & 0,002 & 0,01 & 0,05 \\
\hline
\end{tabular}

essa família também sobressai em riqueza, principalmente em levantamentos na Floresta Ombrófila Densa (Mori et al. 1983, Tabarelli \& Mantovani 1999, Oliveira et al. 2001, são alguns exemplos). Em florestas semideciduais de outras regiões do Brasil, em geral Myrtaceae e Fabaceae apresentam grande riqueza específica (Gandolfi et al. 1995, Ivanauskas et al. 1999, Carvalho et al. 2000, Durigan et al. 2000, Silva \& Nascimento 2001), aliadas a Lauraceae e Euphorbiaceae (Gandolfi et al. 1995, Carvalho et al. 2000). Na área estudada, excetuando-se Fabaceae, as demais famílias citadas também se destacaram em riqueza.

Reitz et al. (1983) cita a ocorrência de oito espécies de Fabaceae para a região da Serra do Sudeste, no entanto, somente uma espécie foi amostrada no presente estudo. Esta constatação também contrasta fortemente com o ocorrido nas florestas estacionais deciduais, que estão mais sujeitas à influência do contingente mesófilo (estacional) de espécies e nas quais Fabaceae assume o primeiro lugar em riqueza (Vasconcellos et al. 1992,
Farias et al. 1994, Jarenkow \& Waechter 2001). Contudo, essa característica já havia sido detectada por Souza (2001) em um levantamento mais ao sul na encosta da Serra do Sudeste, que não registrou espécies de Fabaceae. O fato das espécies de leguminosas provenientes do corredor formado pela Floresta Estacional do Alto Uruguai estarem pouco representadas nas encostas da Serra do Sudeste é intrigante, uma vez que, no centro do estado, ao longo de toda a encosta meridional da Serra Geral, estas espécies alcançam grande expressão (Farias et al. 1994, Bencke \& Soares 1998, Jarenkow \& Waechter 2001).

A maioria das espécies amostradas no presente estudo é de ampla distribuição no estado, ou seja, são espécies encontradas em praticamente todos os tipos de formações florestais, concordando com as considerações de Jarenkow \& Waechter (2001) sobre a importância desse grupo de grande amplitude ecológica nas matas estacionais no sul do Brasil. Dentre as espécies que apresentaram os maiores valores de importância, podem ser consideradas de ampla distribuição 
Tabela 4. Dados de alguns levantamentos fitossociológicos realizados em florestas estacionais no Rio Grande do Sul e em outros estados no Brasil, incluindo o presente estudo, em ordem crescente de latitude (DAP = diâmetro à altura do peito mínimo para inclusão, $\mathrm{S}$ = riqueza específica, H' = índice de diversidade de Shannon, J' = equabilidade).

Table 4. Data of some phytosociological surveys carried out in seasonal forests in Rio Grande do Sul and in another states in Brazil, including the present study, in an increasing latitudinal order (DAP = minimum diameter at breast height, $\mathrm{S}=\mathrm{species}$ richness, H' = Shannon's diversity index, J' = equability).

\begin{tabular}{|c|c|c|c|c|c|c|}
\hline Local/Coordenadas & Método amostral & $\begin{array}{l}\text { DAP } \\
(\mathrm{cm})\end{array}$ & $\mathrm{S}$ & $\begin{array}{c}\mathrm{H}^{\prime} \\
\text { (nats) }\end{array}$ & $\mathrm{J}$ & Referência \\
\hline $\begin{array}{l}\text { S. F. do Itabapoana (RJ) } \\
21^{\circ} 24^{\prime} \mathrm{S} 41^{\circ} 04^{\prime} \mathrm{W}\end{array}$ & $\begin{array}{l}\text { Parcelas } \\
\text { (1 ha) }\end{array}$ & 10 & 83 & 3,21 & 0,77 & Silva \& Nascimento 2001 \\
\hline $\begin{array}{l}\text { Gália (SP) } \\
22^{\circ} 22^{\prime} \mathrm{S} 49^{\circ} 40^{\prime} \mathrm{W}\end{array}$ & $\begin{array}{c}\text { Parcelas } \\
(0,6 \text { ha })\end{array}$ & 5 & 62 & 2,41 & - & Durigan et al. 2000 \\
\hline $\begin{array}{l}\text { Itatinga (SP) } \\
23^{\circ} 17^{\prime} \mathrm{S} 48^{\circ} 33^{\prime} \mathrm{W}\end{array}$ & $\begin{array}{l}\text { Parcelas } \\
(0,42 \text { ha })\end{array}$ & 4,8 & 97 & 3,77 & 0,82 & Ivanauskas et al. 1999 \\
\hline $\begin{array}{l}\text { Guarulhos (SP) } \\
23^{\circ} 25^{\prime} \mathrm{S} 46^{\circ} 28^{\prime} \mathrm{W}\end{array}$ & $\begin{array}{c}\text { Parcelas } \\
(2,7 \text { ha })\end{array}$ & 10 & 113 & 3,73 & - & Gandolfi et al. 1995 \\
\hline $\begin{array}{l}\text { Londrina (PR) } \\
23^{\circ} 27^{\prime} \mathrm{S} 51^{\circ} 15^{\prime} \mathrm{W}\end{array}$ & $\begin{array}{l}\text { Parcelas } \\
\text { (1 ha) }\end{array}$ & 5 & 100 & 3,69 & - & Soares Silva \& Barroso 1992 \\
\hline $\begin{array}{l}\text { Derrubadas (RS) } \\
27^{\circ} 20^{\prime} \mathrm{S} 54^{\circ} 10^{\prime} \mathrm{W}\end{array}$ & $\begin{array}{l}\text { Quadrantes } \\
\text { (107 pontos) }\end{array}$ & 10 & 60 & 3,52 & 0,86 & Vasconcellos et al. 1992 \\
\hline $\begin{array}{l}\text { Vale do Sol (RS) } \\
29^{\circ} 34^{\prime} \mathrm{S} 52^{\circ} 40^{\prime} \mathrm{W}\end{array}$ & $\begin{array}{l}\text { Parcelas } \\
\text { (1 ha) }\end{array}$ & $\begin{array}{c}5 \\
10\end{array}$ & $\begin{array}{l}55 \\
52\end{array}$ & $\begin{array}{l}2,24 \\
2,63\end{array}$ & $\begin{array}{l}0,56 \\
0,67\end{array}$ & Jarenkow \& Waechter 2001 \\
\hline $\begin{array}{l}\text { Santa Cruz do Sul (RS) } \\
29^{\circ} 43^{\prime} \mathrm{S} 52^{\circ} 25^{\prime} \mathrm{W}\end{array}$ & $\begin{array}{c}\text { Parcelas } \\
(0,3 \text { ha })\end{array}$ & 10 & 44 & 3,22 & - & Bencke \& Soares 1998 \\
\hline $\begin{array}{l}\text { Camaquã (RS) } \\
30^{\circ} 41^{\prime} \mathrm{S} 51^{\circ} 52^{\prime} \mathrm{W}\end{array}$ & $\begin{array}{l}\text { Parcelas } \\
\text { (1 ha) }\end{array}$ & $\begin{array}{c}5 \\
10\end{array}$ & $\begin{array}{l}69 \\
64\end{array}$ & $\begin{array}{l}3,20 \\
3,55\end{array}$ & $\begin{array}{l}0,76 \\
0,85\end{array}$ & Presente estudo \\
\hline
\end{tabular}

Gymnanthes concolor e Sorocea bonplandii, ocupantes do sub-bosque, assim como Myrsine umbellata, Sebastiania commersoniana e Casearia sylvestris, que alcançaram o dossel na floresta estudada. As três últimas são consideradas também de ocorrência muito comum nas matas de restinga arenosa (Waechter 1985), sendo que $S$. commersoniana é uma das espécies mais típicas das matas de restinga (Dillenburg et al. 1992, Waechter et al. 2000), demonstrando sua grande amplitude ecológica ao ser também uma das principais espécies num estudo realizado em Floresta Ombrófila Mista (Jarenkow \& Baptista 1987).

A mata estudada apresenta algumas semelhanças estruturais com outra floresta estacional, igualmente de encosta, situada na porção central do estado (município de Vale do Sol) na qual Jarenkow \& Waechter (2001) empregaram os mesmos métodos utilizados no presente estudo. Nesta área, G. concolor e $S$. bonplandii também se destacaram em valor de importância, tendo ocorrido em densidades ainda maiores do que as encontradas na mata estudada. Nas duas áreas, Trichilia claussenii, Hennecartia omphalandra e Eugenia rostrifolia estão entre as espécies mais representativas do contingente mesófilo (ou estacional). Da mesma forma, Schefflera morototoni é outra espécie deste contingente que, apesar do baixo número de indivíduos amostrados em ambas as áreas, destacou-se no dossel pelo grande porte que alcança.

A presença de diversas espécies de Fabaceae no dossel em Vale do Sol (Jarenkow \& Waechter 2001) é uma das principais diferenças estruturais entre ambas as áreas, refletida na classificação destas matas em estacional decidual (Vale do Sol) e semidecidual (área estudada), uma vez que essas leguminosas são espécies caducifólias (Teixeira et al. 1986). O fato de algumas dessas leguminosas serem emergentes também explica as maiores alturas alcançadas por alguns indivíduos em Vale do Sol (entre $25 \mathrm{~m}$ e $27 \mathrm{~m}$ ) (Jarenkow \& Waechter 2001) em comparação às estimativas de altura realizadas neste estudo.

A freqüência de afloramentos rochosos na mata estudada certamente foi um fator limitante para o 


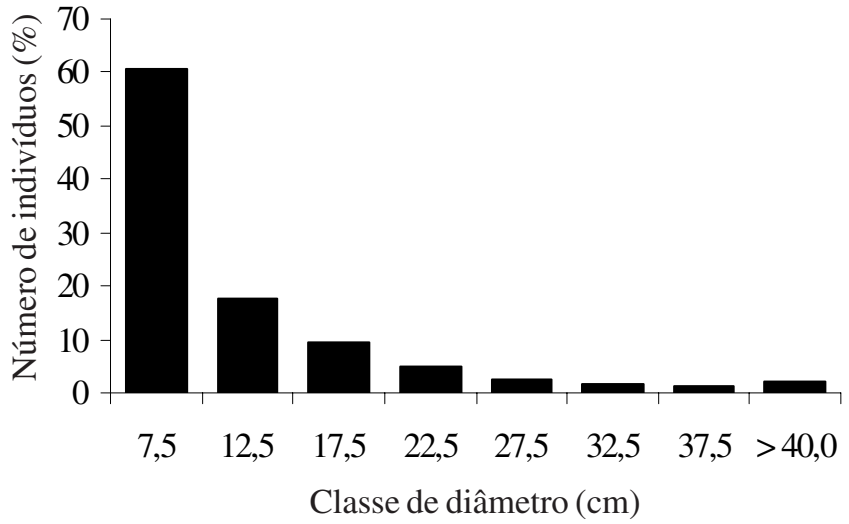

Figura 2. Proporção do número de indivíduos arbóreos amostrados na mata de encosta em Camaquã (RS) por classes de diâmetro de $5 \mathrm{~cm}$. As classes estão expressas pelo valor central; a última agrupa todos os indivíduos com diâmetro a partir de $40 \mathrm{~cm}$.

Figure 2. Proportional number of arboreal individuals sampled in the slope forest at Camaquã (RS) by diameter classes of $5 \mathrm{~cm}$. The classes are expressed by the central value; the last one groups all the individuals with diameter from $40 \mathrm{~cm}$ on.

desenvolvimento de indivíduos de maior porte em alguns locais, aumentando a densidade de árvores de pequeno porte, como demonstram a maior densidade total por área e a menor área basal total encontradas, em comparação com Vale do Sol (Jarenkow \& Waechter 2001). As limitações impostas pelas encostas íngremes e com afloramentos rochosos são também descritas por Oliveira et al. (2001) numa área de Floresta Ombrófila Densa de encosta em São Paulo. Da mesma forma, ao comparar as estimativas da densidade arbórea total em diferentes formações florestais no Rio Grande do Sul, Jarenkow \& Waechter (2001) sugerem a existência de um gradiente decrescente a partir das matas de planície para as de encosta e planalto, o que, segundo os autores, possivelmente está relacionado ao porte dos indivíduos.

No estudo realizado em Vale do Sol, a grande abundância de Euterpe edulis (palmiteiro) foi outra diferença marcante em relação ao presente estudo. Esta espécie se constitui no principal representante do contingente de espécies tropicais atlânticas (higrófilas) em Vale do Sol (Jarenkow \& Waechter 2001). Já na área do presente estudo, E. edulis não ocorre, estando o contingente atlântico representado por diversas outras espécies que contribuem com um grande número de indivíduos. Alguns exemplos são: Aiouea saligna, Calyptranthes grandifolia, Faramea marginata, Guapira opposita, Miconia rigidiuscula, Myrcia glabra, Nectandra oppositifolia, Neomitranthes gemballae, Ocotea silvestris e Pachystroma longifolium, entre outras.

Dentre as espécies atlânticas (higrófilas) ora citadas, destaca-se a presença, na área de estudo, de Neomitranthes gemballae e Ocotea silvestris, ambas pouco freqüentes em levantamentos no estado. N. gemballae, considerada endêmica na Floresta Ombrófila Densa em Santa Catarina (Legrand \& Klein 1977), teve sua distribuição ampliada para o Rio Grande do Sul por Sobral (1984) após ter sido coletada em Camaquã (em outra localidade) e na encosta meridional da Serra Geral e, desde então, não havia mais sido registrada no estado. Já $O$. silvestris, recentemente foi considerada nova ocorrência geográfica para o Rio Grande do Sul, coletada numa área de Floresta Ombrófila Densa (Jarenkow \& Sobral 2000), e constatada também em duas áreas de Floresta Estacional Decidual no centro do estado (Nascimento et al. 2000, Jarenkow \& Waechter 2001).

Da mesma forma, Sloanea monosperma e Ilex paraguariensis, principais espécies em área basal no presente estudo, não foram amostradas em muitos dos estudos fitossociológicos já realizados no Rio Grande do Sul (Dillenburg et al. 1992, Vasconcellos et al. 1992, Farias et al. 1994, Bencke \& Soares 1998, Waechter \& Jarenkow 1998, Nascimento et al. 2000, Waechter et al. 2000). Em Floresta Ombrófila Mista, I. paraguariensis é considerada como muito freqüente

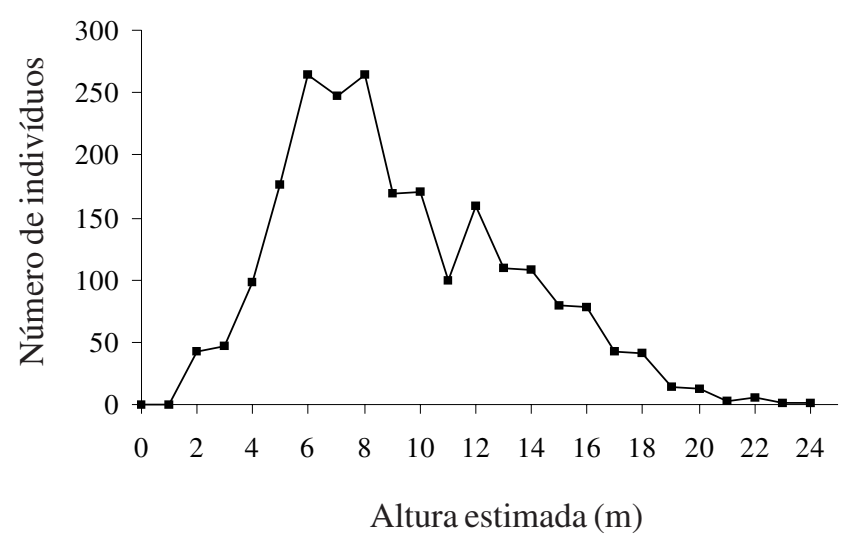

Figura 3. Distribuição vertical do componente arbóreo amostrado na mata de encosta em Camaquã (RS), considerando-se o número de indivíduos total para cada altura estimada, com arredondamento de um em um metro.

Figure 3. Vertical distribution of the arboreal component sampled in the slope forest at Camaquã (RS), considering the total number of individuals to each estimated height, rounded down every meter. 
(Reitz et al. 1983), tendo sido uma das espécies de maior destaque em um levantamento realizado em Erexim (Silverston \& Longhi 1988). Em outra área de Floresta Ombrófila Mista, no município de Muitos Capões, S. monosperma é uma das espécies de maior área basal (Jarenkow \& Baptista 1987).

Embora as estimativas de diversidade de Shannon devam ser comparadas com cautela, devido às ressalvas quanto à dependência desse índice do tamanho amostral e do critério de inclusão, sua utilização é recomendada por ser um bom indicador da diversidade nesse tipo de estudo (Martins 1991, Condit et al. 1996). Considerando-se critérios de inclusão idênticos, a diversidade estimada para a área de estudo é uma das mais altas já registradas em florestas estacionais no estado (tabela 4), com valores praticamente iguais de diversidade e equabilidade aos estimados em Derrubadas, no Alto Uruguai (Vasconcellos et al. 1992). A proximidade entre estas estimativas confirma o destaque da mata estudada em termos de diversidade, uma vez que tanto a Floresta Estacional Decidual do Alto Uruguai como a Floresta Ombrófila Densa são consideradas as formações de maior riqueza arbórea no Rio Grande do Sul (Rambo 1956).

Para outras regiões no Brasil onde há ocorrência de Floresta Estacional Semidecidual, uma série de levantamentos fitossociológicos do componente arbóreo poderiam ser listados (Meira Neto et al. 1998, EspíritoSanto et al. 2002, Lopes et al. 2002, Nunes et al. 2003, são alguns exemplos), muitos deles em áreas de floresta ciliar (Pinto \& Oliveira Filho 1999, Carvalho et al. 2000, Rodrigues et al. 2003, entre outros). No entanto, os métodos empregados nesses trabalhos são variáveis, utilizando diferentes maneiras de disposição das unidades amostrais, bem como distintas áreas totais amostradas e critérios de inclusão. Assim sendo, para comparação com o presente estudo foram selecionados alguns trabalhos que empregam métodos semelhantes, excetuando-se os realizados em florestas ciliares (tabela 4), já que estas caracteristicamente possuem grande heterogeneidade ambiental, o que se reflete na sua estrutura (Rodrigues \& Shepherd 2000). Através dessas comparações, observa-se que a área de estudo situa-se em um contexto de diversidade similar ao de outras regiões do país, embora esteja localizada quase no limite sul de ocorrência destas formações e apresente baixíssima riqueza de leguminosas, uma família tão importante nessas matas.

Em relação a outras florestas estacionais no Rio Grande do Sul, pode-se concluir, a partir dos parâmetros fitossociológicos utilizados para descrever a estrutura, que a floresta estudada é muito similar às florestas deciduais da região central do estado, diferindo, no entanto, em riqueza específica e, conseqüentemente, em diversidade. $\mathrm{O}$ diferencial da área estudada, em termos de diversidade, é a presença de espécies do contingente atlântico (higrófilas), uma vez que as espécies de ampla distribuição diferem pouco e que as leguminosas, principais representantes do contingente mesófilo ou estacional, têm uma participação ínfima no local. A participação de espécies atlânticas na composição florística local pode ser uma conseqüência da maior proximidade da área de estudo a esse corredor de imigração e demonstra a importância da conservação das matas nas encostas das Serras Geral e do Sudeste para a manutenção da diversidade das florestas na metade sul do Rio Grande do Sul.

Agradecimentos - Ao Programa de Pós-Graduação em Botânica da UFRGS, pela oportunidade de realização deste trabalho; ao $\mathrm{CNPq}$, pela bolsa concedida à primeira autora; a Luiz Carlos Barbosa Lessa (in memoriam) e Nilza Lessa, por possibilitarem o acesso à área de estudo; a Jules Soares, Leandro Kerber e Patrick Colombo, pelo auxílio nos trabalhos de campo; aos especialistas Marcos Sobral (Myrtaceae, entre outras) e Maria de Fátima Freitas (Myrsinaceae), pela determinação de algumas espécies.

\section{Referências bibliográficas}

APG II (ANGIOSPERM PHYLOGENY GROUP). 2003. An update of the Angiosperm Phylogeny Group classification for the orders and families of flowering plants: APG II. Botanical Journal of the Linnean Society 141:399-436.

BENCKE, C.S.C. \& SOARES, J. 1998. Estudo fitossociológico da vegetação arbórea de uma área de floresta estacional em Santa Cruz do Sul, RS, Brasil. Caderno de Pesquisa, Série Botânica, 10:37-57.

CARVALHO, D.A., OLIVEIRAFILHO, A.T., VILELA, E.A. \& CURI, N. 2000. Florística e estrutura da vegetação arbórea de um fragmento de floresta semidecidual às margens do reservatório da Usina Hidrelétrica Dona Rita (Itambé do Mato Dentro, MG). Acta Botanica Brasilica 14:37-55.

CONDIT, R., HUBBELL, S.P., LAFRANKIE, J.V., SUKUMAR, R., MANOKARAN, N., FOSTER, R.B. \& ASHTON, P.S. 1996. Species-area and species-individual relationships for tropical trees: a comparison of three 50-ha plots. Journal of Ecology 84:549-562.

CONSÓRCIO MATA ATLÂNTICA \& UNICAMP (orgs.). 1992. Reserva da Biosfera da Mata Atlântica. Plano de ação: referências básicas. Editora da Unicamp, Campinas. 
DILLENBURG, L.R., WAECHTER, J.L. \& PORTO, M.L. 1992. Species composition and structure of a sandy coastal plain forest in northern Rio Grande do Sul, Brazil. In Coastal plant communities of Latin America (U. Seeliger, ed.). Academic Press, San Diego, p.349-366.

DURIGAN, G., FRANCO, G.A.D.C., SAITO, M. \& BAITELLO, J.B. 2000. Estrutura e diversidade do componente arbóreo da floresta na Estação Ecológica dos Caetetus, Gália, SP. Revista Brasileira de Botânica 23:369-381.

ESPÍRITO-SANTO, F.B., OLIVEIRA FILHO, A.T., MACHADO, E.L.M., SOUZA, J.S., FONTES, M.A.L. \& MARQUES, J.J.G.S.M. 2002. Variáveis ambientais e a distribuição de espécies arbóreas em um remanescente de Floresta Estacional Semidecídua Montana no Campus da Universidade Federal de Lavras, MG. Acta Botanica Brasilica 16:331-356.

FARIAS, J.A.C., TEIXEIRA, I.F., PES, L. \& ALVAREZ FILHO, A.A. 1994. Estrutura fitossociológica de uma floresta estacional decidual na região de Santa Maria, RS. Ciência Florestal 4:109-128.

FIDALGO, O. \& BONONI, V.L.R. (coords.). 1984. Técnicas de coleta, preservação e herborização de material botânico. Manual 4. Instituto de Botânica, São Paulo.

FUNDAÇÃO SOS MATA ATLÂNTICA, INSTITUTO NACIONAL DE PESQUISAS ESPACIAIS \& INSTITUTO SOCIOAMBIENTAL. 1998. Atlas da evolução dos remanescentes florestais e ecossistemas associados do Domínio da Mata Atlântica no período de 1990-1995. Fundação SOS Mata Atlântica, São Paulo.

GANDOLFI, S., LEITÃO FILHO, H.F. \& BEZERRA, C.L. 1995. Levantamento florístico e caráter sucessional das espécies arbustivo-arbóreas de uma floresta mesófila semidecídua no município de Guarulhos, SP. Revista Brasileira de Biologia 55:753-767.

GUADAGNIN, D.L., LAROCCA, J. \& SOBRAL, M. 2000. Flora vascular de interesse para a conservação da bacia do arroio João Dias: avaliação ecológica rápida. In Minas do Camaquã (L.R. Ronchi \& A.O.C. Lobato, orgs.). Unisinos, São Leopoldo, p.71-84.

HOLDRIDGE, L.R., GRENKE, W.C., HATHEWAY, W.H., LIANG, T. \& TOSI JUNIOR, J.A. 1971. Forest environment in tropical life zones: a pilot study. Pergamon, Oxford.

IHERING, H. VON. 1891. As árvores do Rio Grande do Sul. In Annuário do Estado do Rio Grande do Sul para o anno de 1892 (G. A. Azambuja, ed.). Gundlach \& Krahe, Porto Alegre, p.164-196.

IVANAUSKAS, N.M., RODRIGUES, R.R. \& NAVE, A.G 1999. Fitossociologia de um trecho de Floresta Estacional Semidecidual em Itatinga, São Paulo, Brasil. Scientia Forestalis 56:83-99.

JARENKOW, J.A. 1994. Estudo fitossociológico comparativo entre duas áreas com mata de encosta no Rio Grande do Sul. Tese de doutorado, Universidade Federal de São Carlos, São Carlos.

JARENKOW, J.A. \& BAPTISTA, L.R.M. 1987. Composição florística e estrutura da mata com araucária na Estação Ecológica de Aracuri, Esmeralda, Rio Grande do Sul. Napaea 3:9-18.
JARENKOW, J.A. \& SOBRAL, M. 2000. Nota sobre a ocorrência de algumas angiospermas no Rio Grande do Sul, Brasil. Napaea 12:5-20.

JARENKOW, J.A. \& WAECHTER, J.L. 2001. Composição, estrutura e relações florísticas do componente arbóreo de uma floresta estacional no Rio Grande do Sul, Brasil. Revista Brasileira de Botânica 24:263-272.

KAGEYAMA, P. \& GANDARA, F.B. 2000. Revegetação de áreas ciliares. In Matas Ciliares: conservação e recuperação (R.R. Rodrigues \& H.F. Leitão Filho, eds.). Editora da Universidade de São Paulo/Fapesp, São Paulo, p.249-269.

KAUL, P.F.T. 1990. Geologia. In Geografia do Brasil (O.V. Mesquita, coord.). Instituto Brasileiro de Geografia e Estatística, Rio de Janeiro, v.2, p.29-54.

KENT, M. \& COKER, P. 1992. Vegetation description and analysis: a practical approach. Belhaven, London.

KER, J.C., ALMEIDA, J.A., FASOLO, P.J. \& HOCHMÜLLER, D.P. 1986. Pedologia. In Levantamento de recursos naturais. Instituto Brasileiro de Geografia e Estatística, Rio de Janeiro, v.33, p.405-540.

LEGRAND, C.D. \& KLEIN, R.M. 1977. Mirtáceas. In Flora Ilustrada Catarinense (R. Reitz, ed.). Herbário Barbosa Rodrigues, Itajaí, p.572-730.

LEITE, P.F. 1995. As diferentes unidades fitoecológicas da Região Sul do Brasil: proposta de classificação. Cadernos de Geociências 15:73-164.

LINDMAN, C.A.M. 1906. A vegetação no Rio Grande do Sul. Universal, Porto Alegre.

LOPES, W.P., SILVA, A.F., SOUZA, A.L. \& MEIRA NETO, J.A.A. 2002. Estrutura fitossociológica de um trecho de vegetação arbórea no Parque Estadual do Rio Doce Minas Gerais, Brasil. Acta Botanica Brasilica 16:443-456.

MARTINS, F.R. 1991. Estrutura de uma floresta mesófila. Editora da Universidade Estadual de Campinas, Campinas.

MEIRA NETO, J.A.A., SOUZA, A.L., SILVA, A.F. \& PAULA, A. 1998. Estrutura de uma Floresta Estacional Semidecidual insular em área diretamente afetada pela Usina Hidrelétrica de Pilar, Guaraciaba, Zona da Mata de Minas Gerais. Revista Árvore 22:179-184.

MORENO, J.A. 1961. Clima do Rio Grande do Sul. Secretaria da Agricultura do Rio Grande do Sul, Porto Alegre.

MORI, S.A., BOOM, B.M., CARVALHO, A.M. \& SANTOS, T.S. 1983. Ecological importance of Myrtaceae in an eastern brazilian wet forest. Biotropica 15:68-70.

MUELLER-DOMBOIS, D. \& ELLENBERG H. 1974. Aims and methods of vegetation ecology. John Willey and Sons, New York.

NASCIMENTO, A.R.T., LONGHI, S.J., ALVAREZFILHO, A.A. \& GOMES, G.S. 2000. Análise da diversidade florística e dos sistemas de dispersão de sementes em um fragmento florestal na região central do Rio Grande do Sul, Brasil. Napaea 12:49-67. 
NUNES, Y.R.F., MENDONÇA, A.V.R., BOTEZELLI, L., MACHADO, E.L.M. \& OLIVEIRA FILHO, A.T. 2003. Variações da fisionomia, diversidade e composição de guildas da comunidade arbórea em um fragmento de floresta semidecidual em Lavras, MG. Acta Botanica Brasilica 17:213-229.

OLIVEIRA, R.J., MANTOVANI, W. \& MELO, M.M.R.F. 2001. Estrutura do componente arbóreo-arbustivo da floresta atlântica de encosta, Peruíbe, SP. Acta Botanica Brasilica 15:391-412.

OLIVEIRA FILHO, A.T. \& FONTES, M.A. 2000. Patterns of floristic differentiation among atlantic forests in southeastern Brazil and the influence of climate. Biotropica 32:793-810.

PINTO, J.R.R. \& OLIVEIRAFILHO, A.T. 1999. Perfil florístico e estrutura da comunidade arbórea de uma floresta de vale no Parque Nacional da Chapada dos Guimarães, Mato Grosso, Brasil. Revista Brasileira de Botânica 22:53-67.

RAMBO, B. 1942. A fisionomia do Rio Grande do Sul. Imprensa Oficial, Porto Alegre.

RAMBO, B. 1950. A porta de Torres. Anais Botânicos do Herbário Barbosa Rodrigues 2:125-136.

RAMBO, B. 1956. Der Regenwald am oberen Uruguay. Sellowia 7:183-233.

RAMBO, B. 1961. Migration routes of the south brazilian rain forest. Pesquisas, série Botânica, 12:1-54.

REITZ, R., KLEIN, R.M. \& REIS, A. 1983. Projeto madeira do Rio Grande do Sul. Sellowia 34/35:1-525.

RODRIGUES, L.A., CARVALHO, D.A., OLIVEIRA FILHO, A.T., BOTREL, R.T. \& SILVA, E.A. 2003. Florística e estrutura da comunidade arbórea de um fragmento florestal em Luminárias, MG. Acta Botanica Brasilica 17:71-87.

RODRIGUES, R.R. \& SHEPHERD, G.J. 2000. Fatores condicionantes da vegetação ciliar. In Matas Ciliares: conservação e recuperação (R.R. Rodrigues \& H.F. Leitão Filho, eds.). Editora da Universidade de São Paulo/ Fapesp, São Paulo, p.101-107.

SILVA, G.C. \& NASCIMENTO, M.T. 2001. Fitossociologia de um remanescente de mata sobre tabuleiros no norte do estado do Rio de Janeiro (Mata do Carvão). Revista Brasileira de Botânica 24:51-62.

SILVA, J.M.C. \& TABARELLI, M. 2000. Tree species impoverishment and the future flora of the Atlantic forest of northeast Brazil. Nature 404:72-74.

SILVERSTON, A. \& LONGHI, S.J. 1988. Estudo fitossociológico do Parque Municipal "Longines Malinowski" de Erexim - RS. In Anais do VI Congresso Florestal Estadual (R.A. Longhi \& S.E. Marques, coords.). Prefeitura Municipal de Nova Prata, Nova Prata, v.1, p.527-540.
SOARES-SILVA, L.H. \& BARROSO, G.M. 1992. Fitossociologia do estrato arbóreo da floresta na porção norte do Parque Estadual Mata dos Godoy, Londrina, PR, Brasil. In Anais do VIII Congresso da Sociedade Botânica de São Paulo (R.R. Sharif, ed.). Sociedade Botânica de São Paulo, Campinas, p.101-112.

SOBRAL, M. 1984. Neomitranthes gemballae (Legr.) Legr. (Myrtaceae): nova ocorrência para o Rio Grande do Sul, Brasil. Iheringia, série Botânica 32:9-13.

SOUZA, C.A. 2001. Estrutura do componente arbóreo de floresta pluvial subtropical na Serra dos Tapes, sul do Rio Grande do Sul. Dissertação de mestrado, Universidade Federal do Rio Grande do Sul, Porto Alegre.

TABARELLI, M. \& MANTOVANI, W. 1999. A riqueza de espécies arbóreas na floresta atlântica de encosta no Estado de São Paulo (Brasil). Revista Brasileira de Botânica 22:217-223.

TEIXEIRA, M.B., COURA NETO, A.B., PASTORE, U. \& RANGEL FILHO, A.L.R. 1986. Vegetação. As regiões fitoecológicas, sua natureza e seus recursos econômicos. Estudo fitogeográfico. In Levantamento de recursos naturais. Instituto Brasileiro de Geografia e Estatística, Rio de Janeiro, v. 33, p.541-632.

TOMÉ JÚNIOR, J.B. 1997. Manual para interpretação de análise de solo. Livraria Editora Agropecuária, Guaíba.

TRYON, R.M. \& TRYON, A.F. 1982. Ferns and allied plants with special reference to tropical America. SpringerVerlag, New York.

VASCONCELLOS, J.M.O., DIAS, L.L., SILVA, C.P. \& SOBRAL, M. 1992. Fitossociologia de uma área de mata subtropical no Parque Estadual do Turvo-RS. Revista do Instituto Florestal 4:252-259.

VELOSO, H.P. \& GÓES FILHO, L. 1982. Fitogeografia brasileira: classificação fisionômico-ecológica da vegetação neotropical. Boletim Técnico Projeto Radambrasil, Série Vegetação 1:1-80.

WAECHTER, J.L. 1985. Aspectos ecológicos da vegetação de restinga no Rio Grande do Sul, Brasil. Comunicação do Museu de Ciências da PUCRS, série Botânica, 33:49-68.

WAECHTER, J.L. \& JARENKOW, J.A. 1998. Composição e estrutura do componente arbóreo nas matas turfosas do Taim, Rio Grande do Sul. Biotemas 11:45-69.

WAECHTER, J.L., MÜLLER, S.C., BREIER, T.B. \& VENTURI, S. 2000. Estrutura do componente arbóreo em uma floresta subtropical de planície costeira interna. In Anais do V Simpósio de Ecossistemas Brasileiros (S. Watanabe, coord.). Aciesp, São Paulo, v.3, p.92-112. 